\title{
Role of Neuroimaging in HIV-Associated Neurocognitive Disorders
}

\author{
Mary C. Masters, $\mathrm{BA}^{1}$ Beau M. Ances, MD, $\mathrm{PhD}^{1,2,3}$ \\ ${ }^{1}$ Department of Neurology, School of Medicine, Washington \\ University in St Louis, St Louis, Missouri \\ ${ }^{2}$ Department of Radiology, Washington University in St Louis, St Louis, \\ Missouri \\ ${ }^{3}$ Department of Biomedical Engineering, Washington University in \\ St Louis, St Louis, Missouri
}

Semin Neurol 2014;34:89-102.

\begin{abstract}
Address for correspondence Beau Ances, MD, PhD, Department of Neurology, School of Medicine, Washington University in St Louis, Box 8111, 660 South Euclid Ave, Saint Louis, MO 63110 (e-mail: bances@wustl.edu).
\end{abstract}

\begin{abstract}
Keywords

- human immunodeficiency virus

- neuroimaging

- magnetic resonance spectroscopy

- volumetrics

- diffusion tensor imaging

- functional MRI

Human immunodeficiency virus (HIV) enters the brain soon after seroconversion and can cause HIV-associated neurocognitive disorders (HAND). Although the more severe and progressive forms of HAND are less prevalent due to combination antiretroviral therapy (CART), $\sim 40 \%$ of HIV-infected (HIV+) patients continue to have cognitive impairment. Some HIV+ individuals who have effective plasma HIV-1 RNA suppression with cART still develop HAND. It is often difficult to diagnose HAND in the outpatient setting as detailed neuropsychological performance testing is required. Additional biomarkers that are relatively easy to obtain and clinically relevant are needed for assessing HIV-associated neuropathologic changes. Recently developed noninvasive magnetic resonance imaging (MRI) techniques have great potential to serve as biomarkers. The authors review the application of some of these neuroimaging techniques, magnetic resonance spectroscopy (MRS), volumetric MRI, diffusion tensor imaging (DTI), functional MRI (fMRI), in HIV+ individuals. Each of the neuroimaging methods offers unique insight into mechanisms underlying neuroHIV, could monitor disease progression, and may assist in evaluating the efficacy of particular CART regimens. It is hoped that considerable progress will continue to occur such that some of these neuroimaging methods will be incorporated across multiple sites and included in future HAND guidelines.
\end{abstract}

Human immunodeficiency virus (HIV) affects more than 1 million individuals in the United States and over 40 million people worldwide. ${ }^{1}$ Advances in combination antiretroviral treatment (CART) have transformed HIV from a rapidly fatal disease to a manageable chronic condition..$^{2-4}$ The proportion of older HIV-infected (HIV+) individuals is rapidly growing. More than half of all HIV+ individuals in the United States are expected to be greater than 50 years old by $2015 .^{5}$ HIV infected $(\mathrm{HIV}+)$ individuals receiving cART can now expect to live almost as long as HIV-uninfected (HIV-) individuals. ${ }^{6}$

Despite these advances, eradication of HIV from the brain has not occurred. The prevalence of HIV-associated neurocognitive disorders (HAND) has remained constant ( $~ 40 \%$ ) despite more available and effective antiretrovirals. ${ }^{7,8}$ Soon after seroconversion, HIV rapidly spreads throughout the brain. Some HIV+ individuals who have effective plasma HIV-1 RNA suppression with cART still develop HAND. ${ }^{9}$ The continued presence of HAND in the cART era may result from nonmutually-exclusive factors including irreversible injury prior to initiating cART, persistent HIV-1 RNA in the central nervous system (CNS) compartment, ${ }^{10}$ antiretroviral toxicities, ${ }^{11-13}$ and/or persistent low-level inflammation in the CNS. ${ }^{14}$ A major effort has begun to optimize therapy for HAND by addressing persistent HIV reservoirs and immunologic activation in the brain.
Issue Theme HIV Neurology; Guest Editors, Serena Spudich, MD, MA, and Ana-Claire Meyer, MD, MSHS
Copyright (c) 2014 by Thieme Medical Publishers, Inc., 333 Seventh Avenue, New York, NY 10001, USA. Tel: +1(212) 584-4662.
DOI http://dx.doi.org/ 10.1055/s-0034-1372346. ISSN $0271-8235$. 
HAND is often difficult to characterize in the typical outpatient visit (15-30 min). Multiple connections throughout the brain are often affected leading to the complex series of clinical signs and symptoms. ${ }^{15}$ Recent criteria have subdivided HAND into three categories: asymptomatic neurocognitive impairment (ANI), mild neurocognitive disorder (MND), and HIV associated dementia (HAD). ${ }^{8}$ These definitions are based upon an individual's performance on neuropsychological performance (NP) testing and self-reported activities of daily living. However, limitations exist with the current HAND criteria. ${ }^{16}$ Often NP testing $(\sim 3 \mathrm{~h})$ is performed in a research setting at certain sites. ${ }^{8} \mathrm{~A}$ continuum of HAND may occur instead of set distinctions. ${ }^{17}$ Unlike other neurodegenerative disorders (i.e., Alzheimer's disease), ${ }^{18}$ additional biomarkers (cerebrospinal fluid [CSF] or neuroimaging) have not been included in the HAND diagnosis. Biomarkers of HAND that are both easy to perform and clinically relevant remain an unmet need.

Neuroimaging techniques may therefore have increased utility in the diagnosis and management of HAND. A variety of novel noninvasive neuroimaging techniques have been developed and hold great promise as they often can be added to conventional sequences. Of note, three magnetic resonance imaging (MRI) techniques have been used in the neuroHIV research setting: metabolic (magnetic resonance spectroscopy [MRS]), structural (MRI volumetrics and diffusion tensor imaging (DTI)), and functional (functional MRI [fMRI]). This review is not meant to be a comprehensive review of all MRI techniques and does not focus on other neuroimaging modalities (e.g., positron emission tomography $[\mathrm{PET}]^{19}$ ).

\section{Cerebral Metabolite Imaging using Magnetic Resonance Spectroscopy}

MRS has been one of the most consistently used neuroimaging methods during the pre- and post-cART eras. ${ }^{20-23} \mathrm{~A}$ current PubMed search reveals more than 75 articles that describe studies that have used this technique to detect HIVassociated changes in cerebral metabolites (key search terms: "MRS," "brain," and "HIV"). Please see - Table 1 for a select list of MRS studies performed in HIV+ patients. MRS detects the signal produced by protons of specific molecules within a volume of brain. Signal amplitude of a particular molecule X $\left(A_{X}\right)$ of interest is proportional to the number of moles of $X$ $\left(\mathrm{N}_{\mathrm{X}}\right)$ with the brain volume $\left(\mathrm{V}_{\mathrm{B}}\right)$ interrogated. Typical molecules measured include (1) N-acetyl aspartate (NAA)- a neuronal marker, (2) choline (Cho)- a marker of cellular proliferation and inflammatory response, $(3)$ creatine $(\mathrm{Cr})$ a measure of brain energy metabolism and reference marker, (4) myo-inositol (MI)- a marker of gliosis, and (5) glutamine (Gln)/glutamate (Glu)- measures of neurotoxicity due to excess $\mathrm{N}$-methyl-D-aspartate (NMDA) receptor activation.

In general, MRS can be performed on conventional MRI scanners, but technical assistance is needed to ensure goodquality scans are obtained. MRS studies should be carefully performed to ensure homogeneity of the magnetic field and suppression of the water signal. ${ }^{24}$ Depending on both the institution and time available for scanning, single- or multi- voxel MRS has been acquired using a variety of acquisition techniques to yield qualitative versus semiquantitative versus quantitative values. Due to quantification limitations, calibration is often performed using a phantom or an internal signal (e.g. water $\left(\mathrm{H}_{2} \mathrm{O}\right)$ or $\mathrm{Cr}$ ). This can result in metabolite ratios rather than absolute concentrations (e.g., $\mathrm{NAA} / \mathrm{Cr}$ ).

Though often limited to certain brain regions (e.g., frontal gray, frontal or parietal white matter, and basal ganglia), MRS provides key insights into the dynamic changes in the brain metabolic profile from primary ( $\leq 1$ year since seroconversion) to chronic ( $>1$ year since seroconversion) infection. Soon after seroconversion, MRS metabolites have been shown to be affected. ${ }^{21,25-27} \mathrm{HIV}+$ patients scanned during the first year of infection have increased $\mathrm{Cho} / \mathrm{Cr}$ in the frontal and white matter ${ }^{21}$ compared with HIV- controls. A subsequent study confirmed these findings with primary HIV + individuals having higher $\mathrm{Cho} / \mathrm{Cr}$ in the basal ganglia compared with HIV- controls. ${ }^{25}$ Observed MRS changes are correlated with markers of CNS infection and inflammation (detectable HIV-1 RNA and chemokines) ${ }^{25}$ and neuronal injury (neurofilament light chain). ${ }^{27}$ Within chronically infected patients, brain metabolite changes are also evident. Many studies have often observed reductions in NAA and concomitant increases in Cho and MI. ${ }^{22,28-31}$ More recent MRS studies performed at higher magnetic fields using newer analysis methods have demonstrated reductions in $\mathrm{Glu}^{32}$ and Gln. ${ }^{29}$ Observed MRS changes in chronically infected HIV+ patients are proportional to the degree of cognitive impairment. ${ }^{22,29}$ While increases in MRS markers of inflammation (Cho and MI) are seen in cognitively normal HIV + patients, greater changes in inflammation (Cho and $\mathrm{MI}$ ) and neuronal loss (NAA/Cr and $\mathrm{Glu} / \mathrm{Cr}$ ) are observed in HAND patients. ${ }^{22,29,32}$

The introduction of cART has dramatically reduced the more severe forms of HAND and can also lead to improvements, but not normalization, of brain metabolites. . $^{31,33,34}$ Early treatment with cART may be neuroprotective and mitigate the early inflammatory changes seen in primary HIV + patients. Commencement of therapy soon after diagnosis normalizes $\mathrm{Cho} / \mathrm{Cr}$ in the basal ganglia within 6 months. ${ }^{26}$ Several clinical trials have started to include MRS markers to evaluate the efficacy of adjunctive therapy for HAND. ${ }^{35}$ This technique may have great potential in future early prevention studies.

Increasing evidence has also suggested that certain antiretrovirals may cause mitochondrial toxicity and lead to neuronal loss. ${ }^{12,36}$ Chronically infected HIV+ patients on CART regimens that included nucleotide reverse transcriptase inhibitors (NRTIs) had significant reductions in NAA in the frontal white matter compared with HIV- controls. HIV+ individuals receiving alternative cART regimens that did not include NRTIs exhibited intermediate decreases in NAA. ${ }^{37} \mathrm{~A}$ more recent study has observed that HIV+ patients receiving NRTIs had reductions in parietal and frontal gray matter Glu that were predictive of worse cognitive performance. ${ }^{32}$

With a larger proportion of HIV+ growing older with the disease, several studies have started to investigate the interaction between HIV and aging using MRS. HIV + patients have been shown to have significant reductions in Glu to levels 


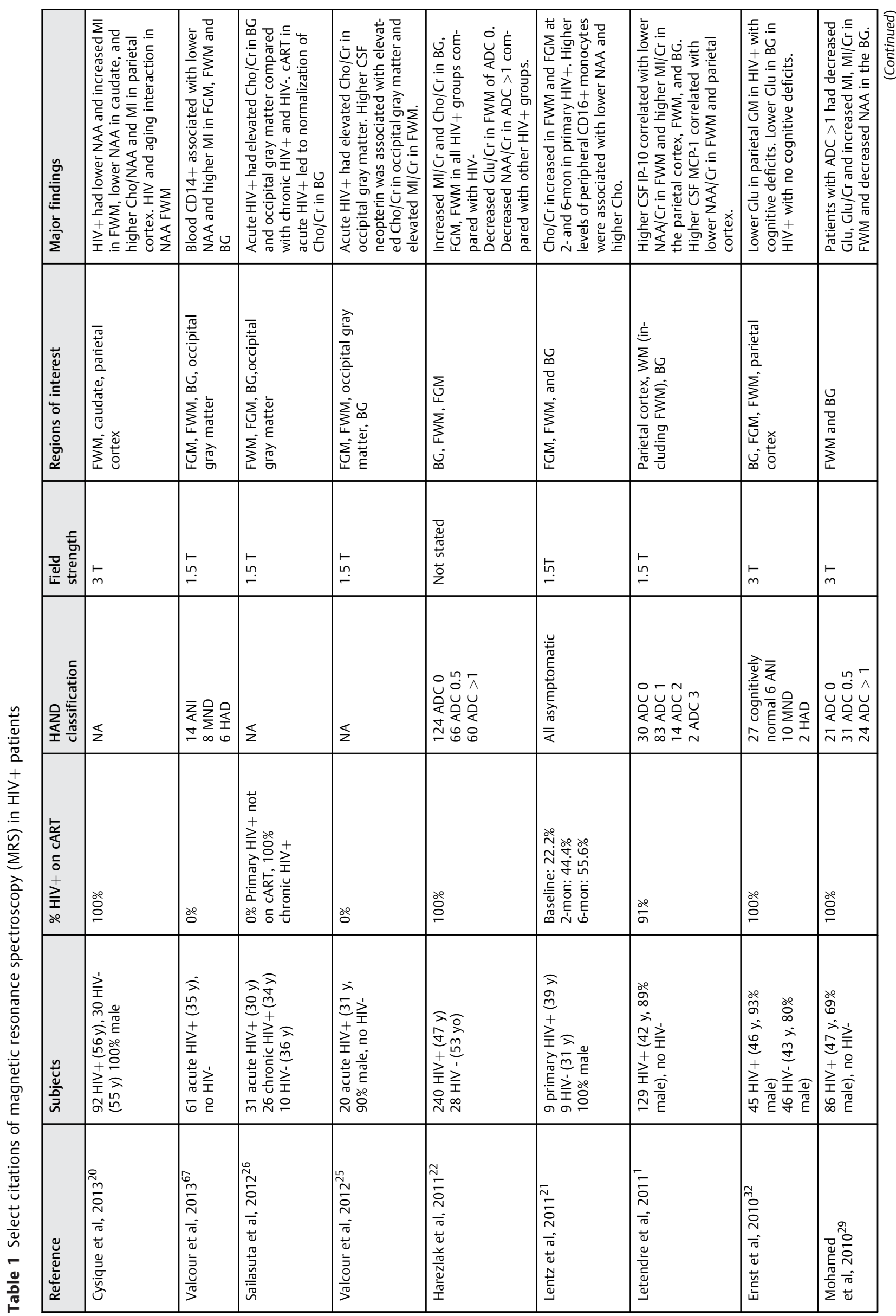


92 Role of Neuroimaging in HIV-Associated Neurocognitive Disorders Masters, Ances

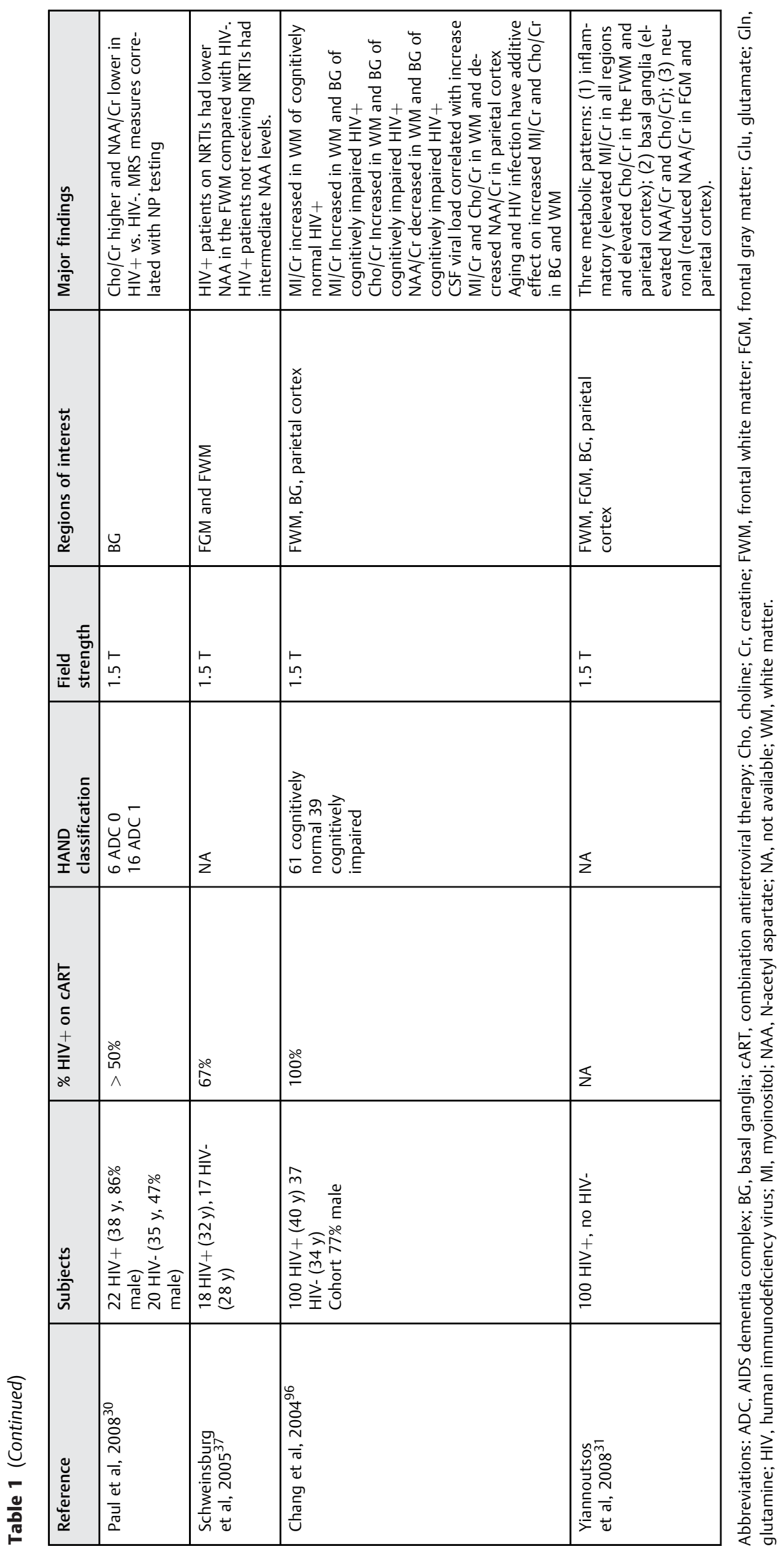

Seminars in Neurology $\quad$ Vol. $34 \quad$ No. $1 / 2014$ 
equivalent to those in HIV- controls a decade older. ${ }^{32}$ Another study confirmed these findings by demonstrating that HIV+ patients exhibited age dependent declines in NAA and Gln, such that the metabolic profile of a 30 -year-old HIV+ patient was equivalent to a 56-year-old HIV- control. ${ }^{22}$ In both instances, though HIV and aging effects were observed, no interaction was present.

Overall, MRS offers a valuable method for monitoring HIVassociated neuropathologic changes. Observed MRS changes may be more sensitive than conventional MRI alone and could augment current neuroimaging protocols. MRS measures may detect subtle early changes associated with HIV infection, and concentrations or ratios of cerebral metabolites measured by MRS could be used as a quantitative indicator of cerebral involvement. In addition, MRS could be used to evaluate the efficacy of therapeutics directed against HIV infection within the CNS during early stages of infection. Some limitations exist in the current MRS HIV research literature, including mostly cross-sectional studies, as well as analyses restricted to specific regions of interest. However, MRS results suggest that contributions of inflammation, aging, and drug toxicity could all contribute to the continued prevalence of HAND. Additional studies that include more HIV- controls are needed. Longitudinal studies, with a focus on repeated imaging of HIV+ patients as they transition through different stages of infection, as well as prior to and after stable cART, are needed. In addition, the impact of comorbidities (e.g., hepatitis, substance abuse, etc.) on MRS measurements should be more fully characterized in HIV+ patients.

\section{Structural Neuroimaging}

\section{Volumetrics Analysis of MRI}

Volumetric MRI examines particular regions of interest and assesses if abnormal structural changes are present in affected individuals compared with healthy controls. ${ }^{38}$ This method provides a useful tool to rule out alternate etiologies and can support a diagnosis of HAND. Specific structures or general brain regions (e.g., white and gray matter) are analyzed. ${ }^{39}$ A PubMed search using keyword search terms "MRI," "volume," "brain," and "HIV" identifies more than 60 articles. Please see - Table $\mathbf{2}$ for a select list of MRI volumetric studies performed in HIV+ patients. Typically, higher field MRI (initially $1.5 \mathrm{~T}$ and now $3 \mathrm{~T}$ ) has been used to acquire high resolution T1-weighted images. In particular, a magnetization prepared rapid acquisition gradient echo (MPRAGE) image provides the greatest contrast for segmenting gray matter, white matter, and CSF. Although not typically acquired with conventional imaging sequences, the MPRAGE sequence can be obtained on most MRI scanners.

Early volumetric work concentrated on measuring ratios of subcortical (e.g., caudate) to intraventricular volumes. This technique could not isolate the location of atrophy and missed brain regions not within the field of view. ${ }^{40}$ Semior fully automated methods have been developed for segmenting the brain based on voxel signal intensity properties of tissues. ${ }^{41-43}$ Currently, a variety of preprocessing pro- grams are available, but some experience is needed for analysis.

In the pre- and early antiretroviral era, significant volume loss was observed in the basal ganglia, posterior cortex, and total white matter of HIV+ patients compared with agematched HIV- individuals. ${ }^{44-46}$ Atrophy was greatest in more advanced stages of infection, but changes were seen even in cognitively normal HIV+ individuals. ${ }^{47}$ Subsequent studies in the cART era have demonstrated subcortical and

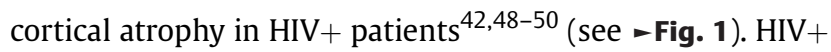
individuals, especially those with an acquired immunodeficiency syndrome- (AIDS-) defining event, have thinner cortical thickness (primary sensory, and motor), ${ }^{49}$ smaller cortical volumes, ${ }^{28,42,49,51,52}$ and larger total ventricular size. ${ }^{49,52}$ Ongoing brain volume loss occurs despite initiation of cART ${ }^{28,50}$ Changes in brain volume may commence early as cortical atrophy and expansion of the third ventricle are observed in primary HIV infection. ${ }^{51}$

Volumetric changes also correlate with NP testing and clinical measures. Several studies have reported structurefunction relations with poorer cognitive or motor performance associated with smaller brain volumes. ${ }^{30,49,53-60}$ Both greater viral burden (plasma HIV-1 RNA, CSF HIV-1 RNA, peripheral monocyte DNA) and immune response to the virus (nadir CD4+ T lymphocyte counts) are associated with greater volume loss. ${ }^{28,42,52,54,55,60-62}$

Common comorbidities may also contribute to volume abnormalities in HIV+ patients. Hepatitis C coinfection, ${ }^{42}$ alcoholism, ${ }^{55}$ cigarette smoking, ${ }^{63}$ and small-vessel disease ${ }^{64}$ may exacerbate brain atrophy in the setting of HIV infection. Furthermore, characteristic volume loss associated with aging may independently affect certain brain structures in older HIV+ individuals..$^{50,55,65,66}$ Older HIV+ individuals suffering from multiple comorbidities may experience greater cumulative volume losses, increasing their risk for HIV-induced neurocognitive impairment. ${ }^{67}$

Overall, MRI volumetric analysis demonstrates that brain structure abnormalities begin early and progress throughout the course of HIV infection. Brain structural integrity in HIV likely reflects dynamic effects of current immune status and active viral replication, superimposed on possible residual effects associated with severe prior immunosuppression and other comorbidities. Though most MRI volumetric studies have been performed cross sectionally, additional longitudinal studies could assess for risk factors for developing HAND and response to therapy. Future studies should include more HIV- controls for comparison.

\section{Diffusion Tensor Imaging}

More recently, diffusion tensor imaging (DTI) has become a popular method for studying white matter structural integrity ${ }^{59,68-70}$ A PubMed search including the keywords "DTI," "brain," and "HIV" identified more than 30 articles. Please see $\boldsymbol{-}$ Table $\mathbf{3}$ for a select list of DTI studies performed in HIV+ patients. DTI measures the diffusion of water molecules in white matter. Movement of water can be anisotropic with diffusion greater along the length of the fiber (longitudinal direction) than perpendicular to it (radial or transverse 


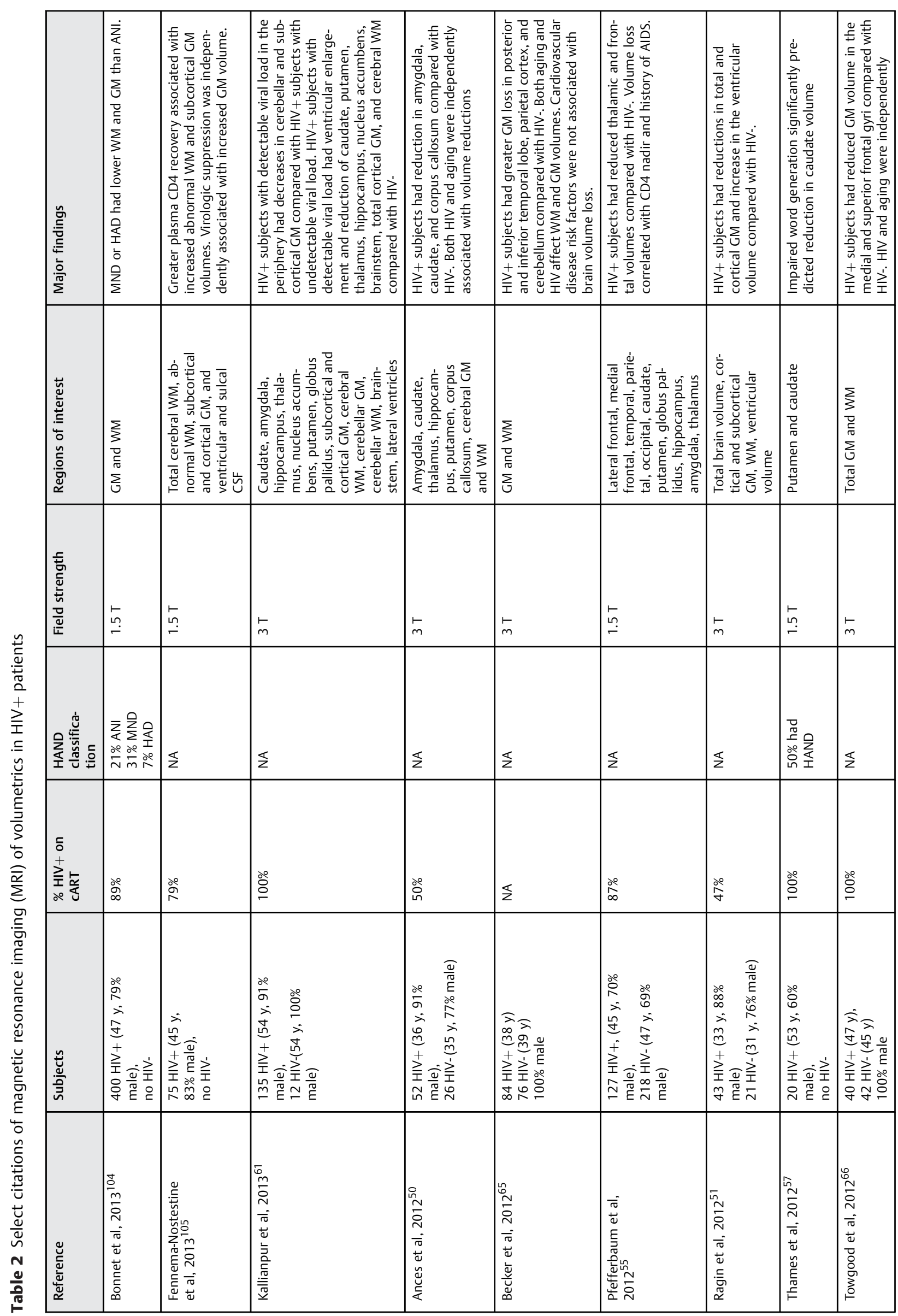




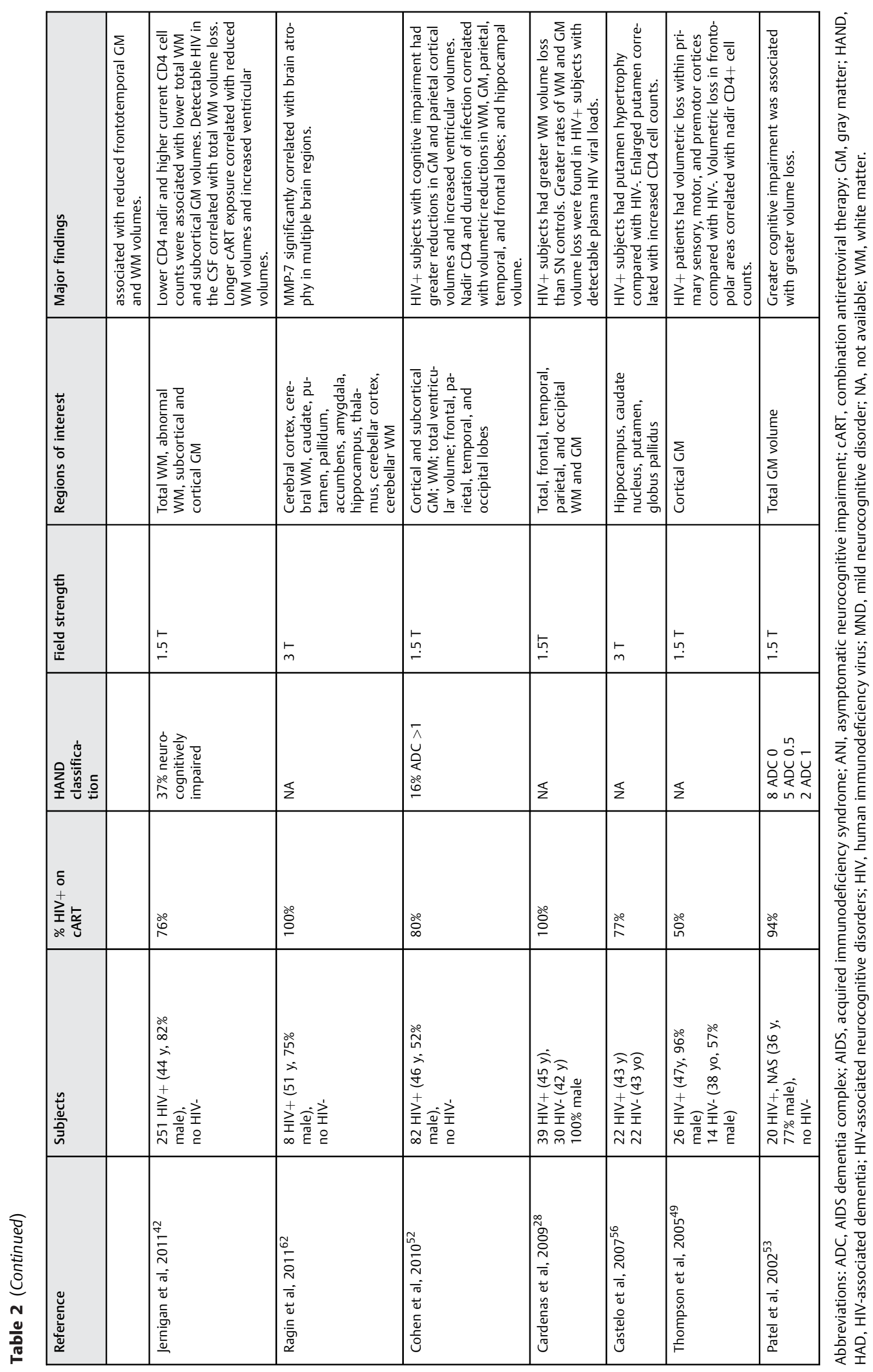



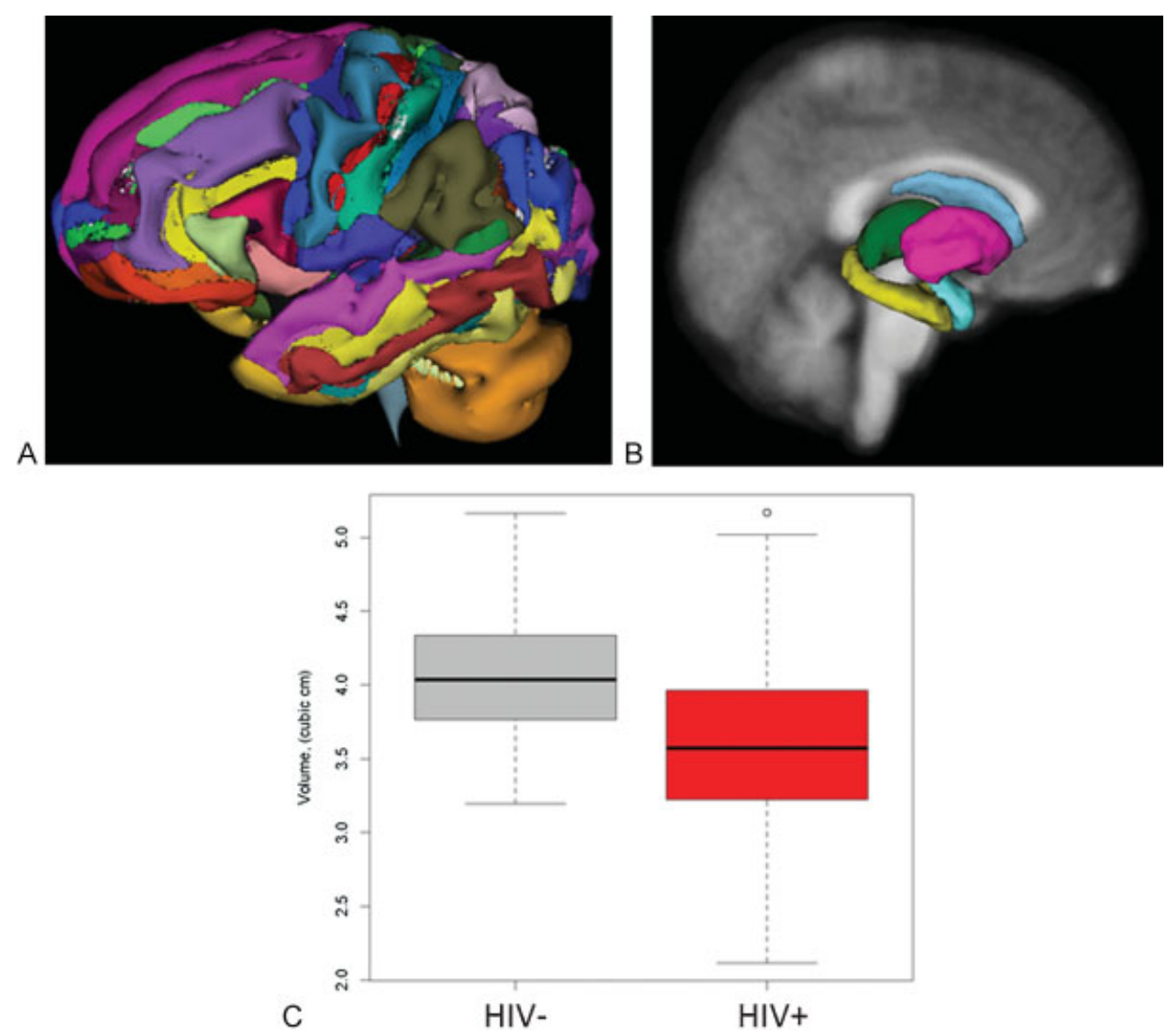

Fig. 1 Freesurfer segmentation of cortical (A) and subcortical (B) regions of the brain. (C) Comparison of volumes from the right caudate for human immunodeficiency virus-negative (HIV-) controls and HIV+ patients. Overall, HIV+ patients had significantly smaller volumes $(p<0.05)$.

direction), as myelin may restrict diffusion. ${ }^{71}$ For each voxel, a tensor is calculated that describes the three-dimensional shape of diffusion of water. The fiber direction is indicated by the tensor's main eigenvector. Diffusion along the major axis is assumed to reflect diffusivity parallel to the white matter tract. Mean diffusivity (MD) reflects the average diffusion in the major axis and the two minor axes. Fractional anisotropy (FA) is a value between zero and one and provides a measure of the general shape of the ellipsoid. ${ }^{72}$

In general, DTI can be performed on conventional MRI scanners, but technical assistance is required. Depending on both the institution and time available for scanning, DTI with either single or multiple diffusion sensitivity parameters ("b values") can be performed. A minimum of six directions is acquired. Conventional preprocessing packages exist, but experience is required for analysis.

Variable results have been observed when DTI has been used to study the effects of HIV on white matter integrity. ${ }^{60,66,68,73-83}$ In general, many studies have shown that HIV leads to an increase in MD and a decrease in FA within white matter tracts (including the corpus callosum [CC] and centrum semiovale [CSO]) (see - Fig. 2). However, subtle differences exist in the location of these changes depending on the study. ${ }^{84-87}$ For example, Filippi and colleagues showed a decrease in FA and an increase in $\mathrm{MD}$ in the genu and splenium of the CC of HIV+ patients. $^{80}$ Thurnher and colleagues observed a reduction in FA within the genu of the CC of HIV+ patients. ${ }^{75} \mathrm{Wu}$ and colleagues reported a reduction in FA within the splenium of the CC in $\mathrm{HIV}+$ individuals. This reduction in FA was associated with worsening motor speed performance. ${ }^{74}$ However, Wright and colleagues observed a reduction in MD throughout the CC and CSO of HIV+ patients compared with HIV- controls. ${ }^{88}$ Instead of region of interest analyses, a voxelwise analysis can also be performed. Gongvtana and colleagues showed significantly higher MD and lower FA throughout the white matter of HIV+ individuals compared with HIVcontrols. ${ }^{73}$

Typically, comparisons have been performed between HIV + and HIV- controls. HIV + individuals receiving cART (HIV+/CART+) and those naïve to cART (HIV+/cART-) have often been merged into a single group. The few studies that have investigated the effects of cART on DTI parameters in HIV + individuals have shown conflicting results. Pffeferbaum and colleagues demonstrated that HIV+/CART- individuals had significantly higher MD values in the inferior cingulate bundle, occipital forceps, and superior longitudinal fasciculus compared with HIV- controls or HIV $+/ \mathrm{cART}+{ }^{83}$ However, Chen and colleagues noted no significant differences in DTI parameters between HIV+/cART- and HIV+/cART+ patients. ${ }^{89} \mathrm{~A}$ decrease in FA was seen in the temporal lobes of $\mathrm{HIV}+/ \mathrm{cART}+$ compared with HIV $+/ \mathrm{cART}$ - individuals, ${ }^{73}$ suggesting possible neurotoxicity. More recently, Wright and colleagues demonstrated that initiation of cART led to 


\begin{tabular}{|c|c|c|c|c|c|c|c|c|c|c|c|c|}
\hline 参 & 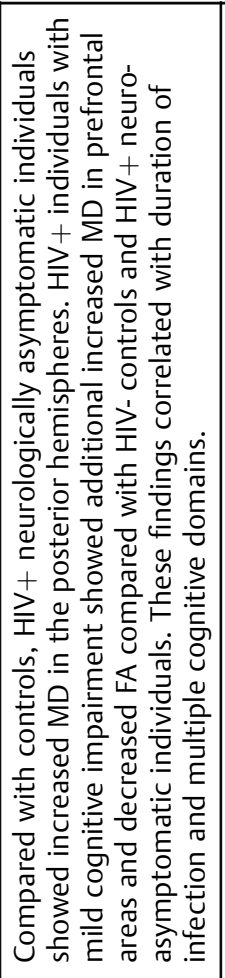 & 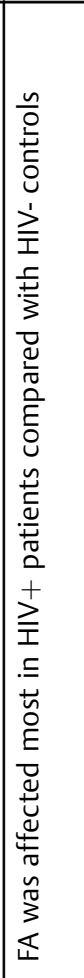 & 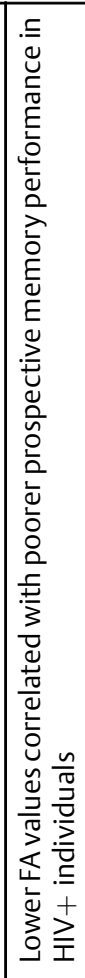 & 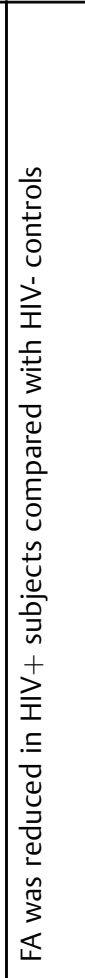 & 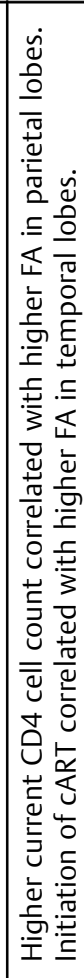 & 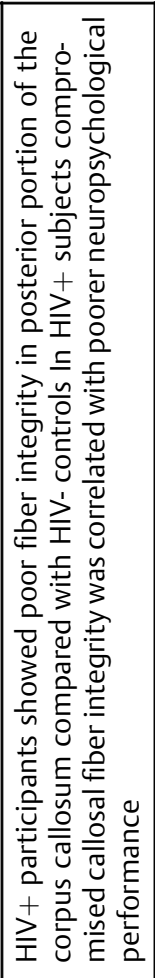 & 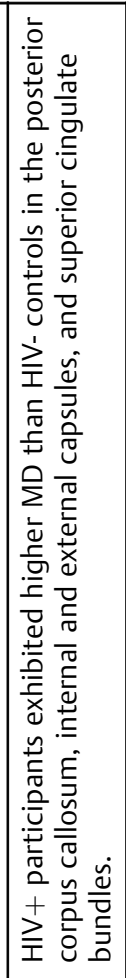 & 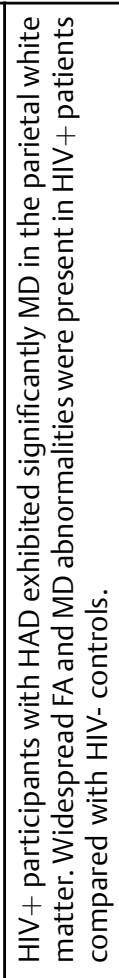 & 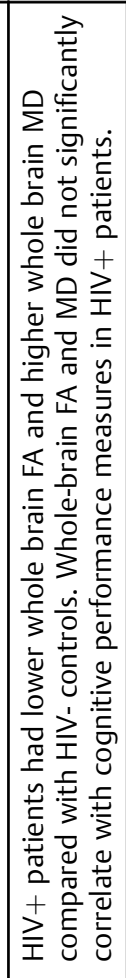 & 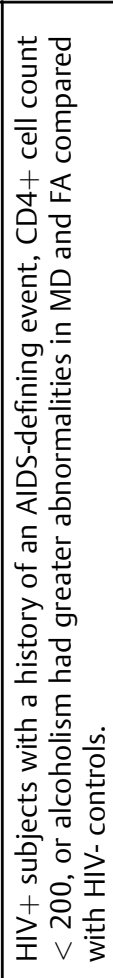 & 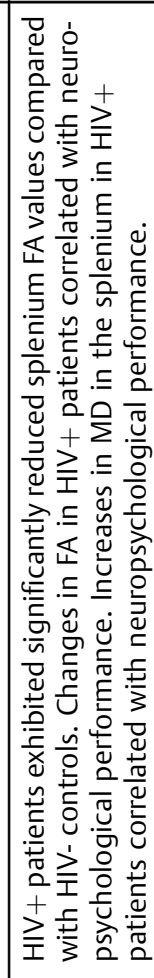 & 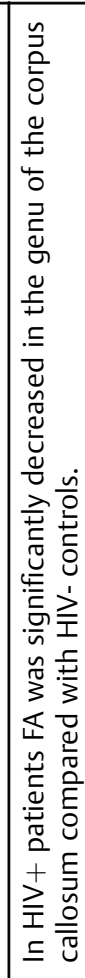 \\
\hline 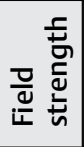 & $\stackrel{\leftarrow}{\llcorner}$ & $\stackrel{\leftarrow}{\llcorner}$ & $\stackrel{\leftarrow}{m}$ & $\stackrel{\leftarrow}{m}$ & $\stackrel{\vdash}{m}$ & $\stackrel{\leftarrow}{\llcorner}$ & $\stackrel{\leftarrow}{\llcorner}$ & $\stackrel{\leftarrow}{m}$ & $\stackrel{\vdash}{\llcorner}$ & \& & $\stackrel{\leftarrow}{\stackrel{\leftarrow}{n}}$ & $\stackrel{\leftarrow}{\longleftarrow}$ \\
\hline 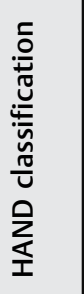 & 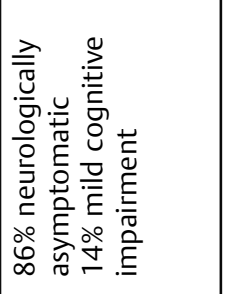 & ¿ & 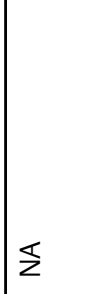 & 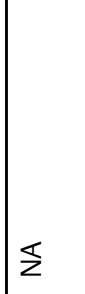 & 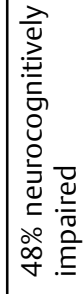 & \& & $\Sigma$ & 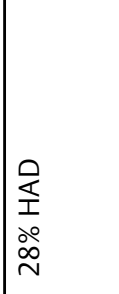 & $\Sigma$ & \& & 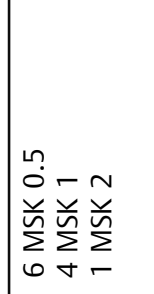 & $\Sigma$ \\
\hline 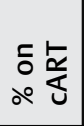 & ○े & ○े & ○े & ळ̊ & $\frac{\stackrel{0}{\infty}}{\infty}$ & $\begin{array}{l}\text { 号 } \\
\text { ọ } \\
\end{array}$ & ஓ̊ & ญें & $\stackrel{\circ}{\stackrel{2}{人}}$ & $\mid \stackrel{\circ 0}{00}$ & ळ̊ & \& \\
\hline 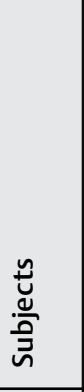 & 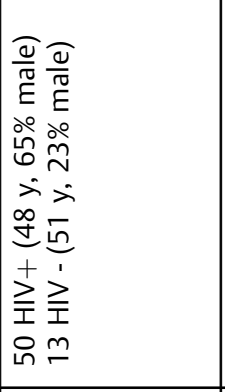 & 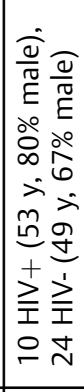 & 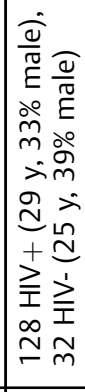 & 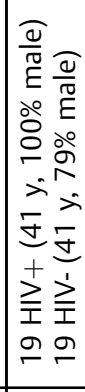 & 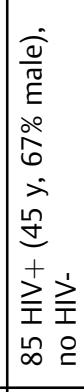 & 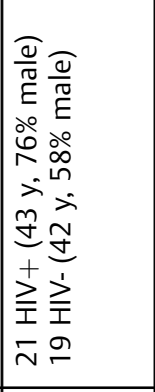 & 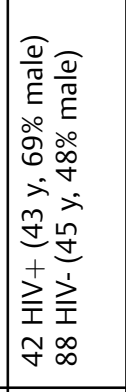 & 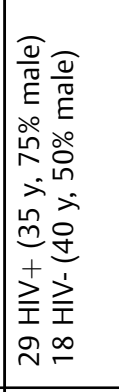 & 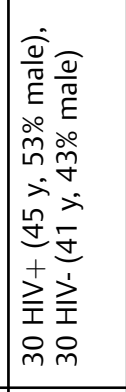 & 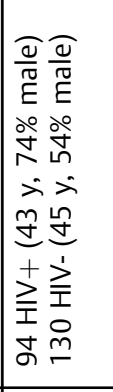 & 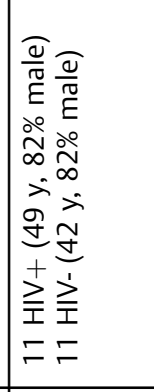 & 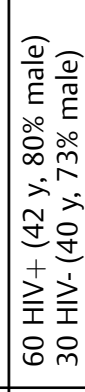 \\
\hline 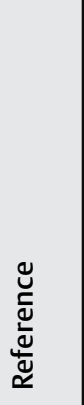 & 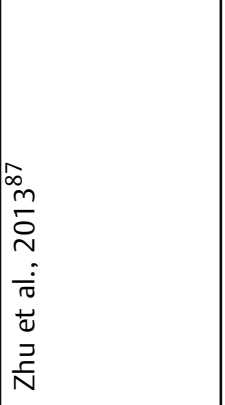 & 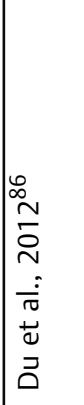 & 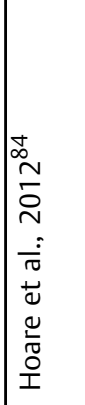 & 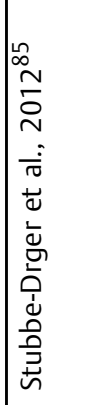 & 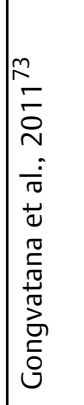 & 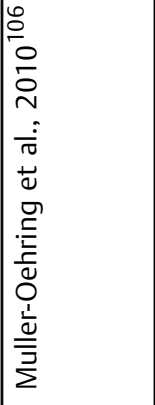 & 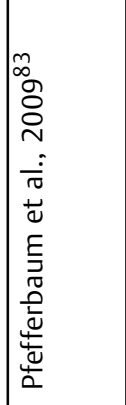 & 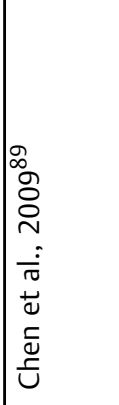 & 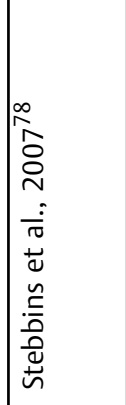 & 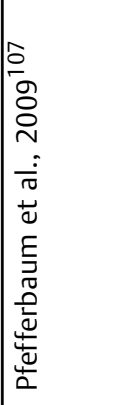 & 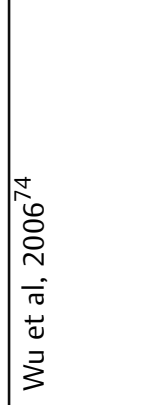 & 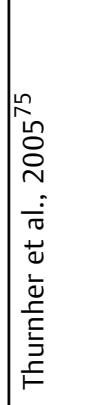 \\
\hline
\end{tabular}




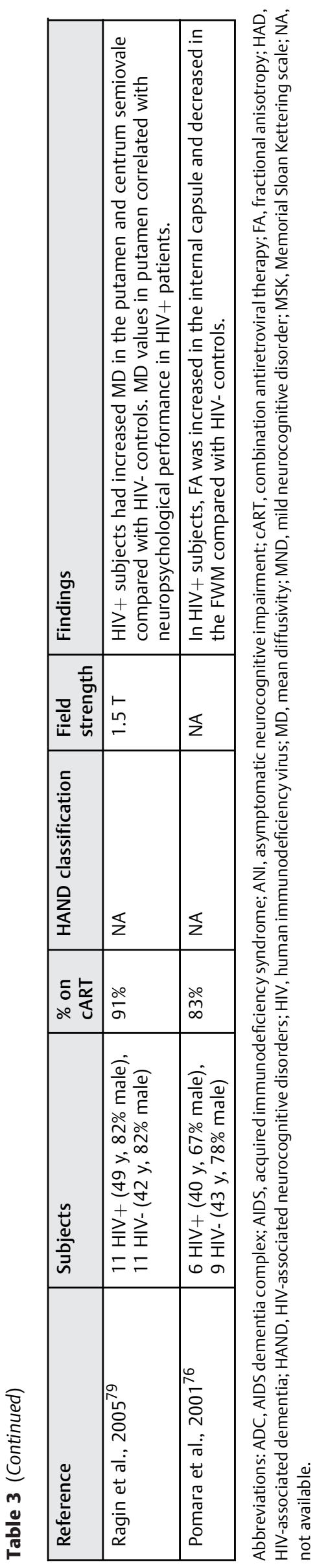

significant increases in MD, but not FA in the CC and CSO of HIV + patients. $^{88}$

In summary, DTI may be a more sensitive method than conventional T2-weighted imaging for detecting subtle changes despite the presence of normal appearing white matter in HIV+ patients. Most DTI studies have been cross sectional, and studied changes in chronic or advanced HIV infection. The effects of early HIV infection or of cART initiation on the white matter have not been systematically assessed by DTI. Furthermore, few DTI studies have included enough HIV- controls. Additional studies comparing DTI parameters to CSF biomarkers and assessing the potential impact of comorbidities need to be performed.

\section{Functional Magnetic Resonance Imaging}

A nascent literature has started to develop utilizing blood oxygen-level dependent (BOLD) fMRI to investigate the effects of HIV on brain function..$^{90}$ A PubMed search using "fMRI," "BOLD," and "HIV" as keyword search terms yielded nine articles. Although the BOLD sequence can be performed on conventional MRI scanners, additional technical assistance is required for designing functional task paradigms. Preprocessing programs are available, but significant experience is needed.

Fluctuations in the BOLD response within specific brain regions indirectly reveal the coupling between changes in neuronal activity and cerebral blood flow for a particular stimulus. ${ }^{91}$ Increases or decreases in brain activation during a task, as compared with rest or a neutral task, are assumed to be related to the cognitive function that is under investigation. ${ }^{92}$ HIV + patients have greater parietal activation for a simple attention task and greater frontal and parietal activation during more complex attention tasks. ${ }^{93}$ These BOLD changes in HIV+ patients may reflect increased recruitment of additional areas to meet cognitive demands $\mathrm{s}^{32,33,56,93-101} \mathrm{~A}$ recent systematic meta-analysis of BOLD fMRI studies using various functional tasks in HIV+ patients was performed using an activation likelihood estimation (ALE). HIV + patients had greater functional activation within the left inferior frontal gyrus and caudate nucleus compared with HIV- controls. ${ }^{102}$ Dysfunction in this frontostriatal network was qualitatively related to neurocognitive impairment. When assessed at rest, functional connections between brain networks may be compromised in HAND, in ways that are similar to aging. ${ }^{103}$

To date, most BOLD fMRI studies have been performed in a limited number of HIV+ patients with most receiving cART. Only a few studies have started to assess the impact of comorbidities such as methamphetamine use. A common task paradigm has not been developed across studies or sites. Additional BOLD fMRI studies are needed to evaluate the efficacy of novel therapies.

\section{The Future of Advanced Neuroimaging}

Considerable progress has been made in applying MRI methods to understand neuroHIV. However, most studies have compared HIV+ individuals to HIV- controls with secondary comparisons concentrating on HAND diagnosis or certain 


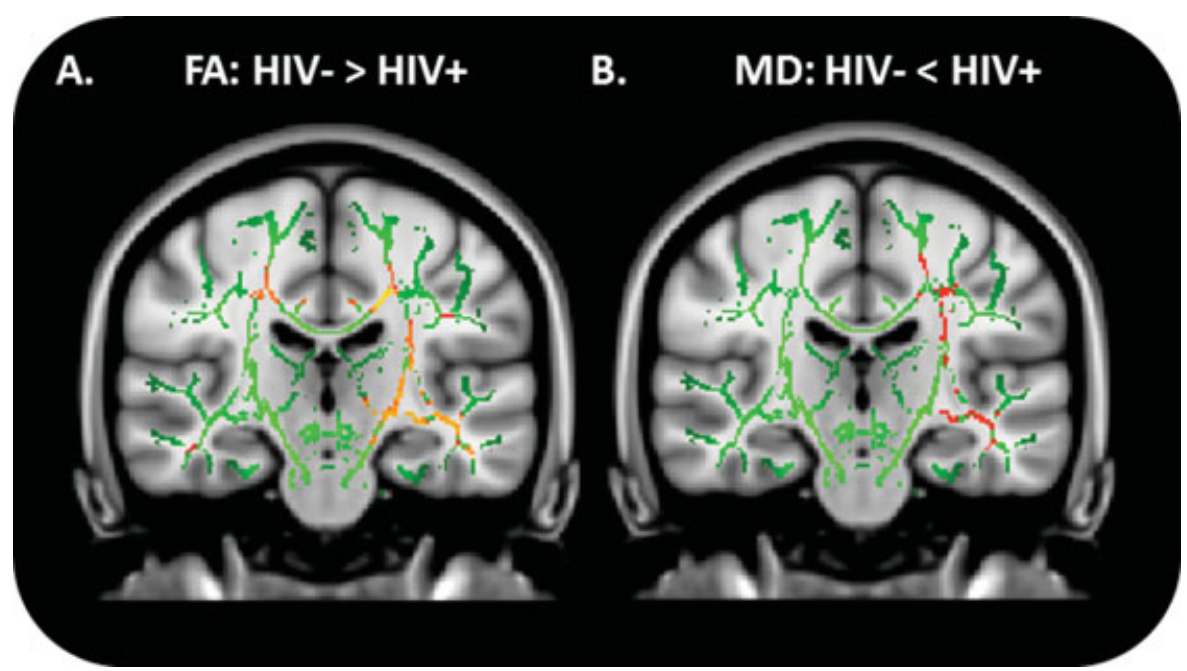

Fig. 2 Voxelwise comparisons for fractional anisotropy (FA) (A) and mean diffusivity (MD) (B) between HIV-controls and HIV+ patients using Tract-Based Spatial Statistics (TBSS). Red: $p=0.05$; Orange: $p=0.03$; Yellow: $p=0.01$.

laboratory measures or comorbidities. Further studies that investigate the pathophysiology of spread of the disease throughout the brain are needed. These studies could help predict which HIV+ patients are at increased risk for developing HAND.

For neuroimaging to take the next step, these techniques need to be included not only within research criteria for HAND, but also in the evaluation of therapeutics. This can be accomplished by using a common protocol at multiple research sites. This protocol should include multiple MRI modalities. A first attempt has been made by the AIDS Clinical Trial Group (ACTG) with multiple sites scanning HIV + patients using the same imaging paradigm. Results from this pilot study were encouraging and it is hoped that a similar protocol can be rolled out to more sites. Crossmodality comparisons within the same HIV+ individual will provide us a more complete understanding of the HIV pathophysiology.

\section{Acknowledgments}

This work was supported by grants R01NR014449, R01NR012657, R01NR012907, R21MH099979, and the Alzheimer's Association (B.M.A.).

\section{References}

1 Letendre SL, Ellis RJ, Everall I, Ances B, Bharti A, McCutchan JA. Neurologic complications of HIV disease and their treatment. Top HIV Med 2009;17(2):46-56

2 Justice AC. HIV and aging: time for a new paradigm. Curr HIV/AIDS Rep 2010;7(2):69-76

3 Holt JL, Kraft-Terry SD, Chang L. Neuroimaging studies of the aging HIV-1-infected brain. J Neurovirol 2012;18(4):291-302

4 Aberg JA, Kaplan JE, Libman H, et al; HIV Medicine Association of the Infectious Diseases Society of America. Primary care guidelines for the management of persons infected with human immunodeficiency virus: 2009 update by the HIV medicine
Association of the Infectious Diseases Society of America. Clin Infect Dis 2009;49(5):651-681

5 Luther VP, Wilkin AM. HIV infection in older adults. Clin Geriatr Med 2007;23(3):567-583, vii

6 Justice AC, Modur SP, Tate JP, et al; NA-ACCORD and VACS Project Teams. Predictive accuracy of the Veterans Aging Cohort Study index for mortality with HIV infection: a North American cross cohort analysis. J Acquir Immune Defic Syndr 2013;62(2): 149-163

7 Heaton RK, Clifford DB, Franklin DR Jr, et al; CHARTER Group. HIVassociated neurocognitive disorders persist in the era of potent antiretroviral therapy: CHARTER Study. Neurology 2010;75(23): 2087-2096

8 Antinori A, Arendt G, Becker JT, et al. Updated research nosology for HIV-associated neurocognitive disorders. Neurology 2007; 69(18):1789-1799

9 Spudich S. HIV and neurocognitive dysfunction. Curr HIV/AIDS Rep 2013;10(3):235-243

10 Ellis RJ, Moore DJ, Childers ME, et al. Progression to neuropsychological impairment in human immunodeficiency virus infection predicted by elevated cerebrospinal fluid levels of human immunodeficiency virus RNA. Arch Neurol 2002;59(6):923-928

11 Liner KJ II, Ro MJ, Robertson KR. HIV, antiretroviral therapies, and the brain. Curr HIV/AIDS Rep 2010;7(2):85-91

12 Marra CM, Zhao Y, Clifford DB, et al; AIDS Clinical Trials Group 736 Study Team. Impact of combination antiretroviral therapy on cerebrospinal fluid HIV RNA and neurocognitive performance. AIDS 2009;23(11):1359-1366

13 Robertson K, Liner J, Meeker RB. Antiretroviral neurotoxicity. J Neurovirol 2012;18(5):388-399

14 Hagberg L, Cinque P, Gisslen M, et al. Cerebrospinal fluid neopterin: an informative biomarker of central nervous system immune activation in HIV-1 infection. AIDS Res Ther 2010;7:15

15 Mind Exchange Working G; Mind Exchange Working Group. Assessment, diagnosis, and treatment of HIV-associated neurocognitive disorder: a consensus report of the mind exchange program. Clin Infect Dis 2013;56(7):1004-1017

16 Gannon P, Khan MZ, Kolson DL. Current understanding of HIVassociated neurocognitive disorders pathogenesis. Curr Opin Neurol 2011;24(3):275-283

17 Valcour V, Paul R, Chiao S, Wendelken LA, Miller B. Screening for cognitive impairment in human immunodeficiency virus. Clin Infect Dis 2011;53(8):836-842 
18 Sperling RA, Aisen PS, Beckett LA, et al. Toward defining the preclinical stages of Alzheimer's disease: recommendations from the National Institute on Aging-Alzheimer's Association workgroups on diagnostic guidelines for Alzheimer's disease. Alzheimers Dement 2011;7(3):280-292

19 Sathekge M, Goethals I, Maes A, van de Wiele C. Positron emission tomography in patients suffering from HIV-1 infection. Eur J Nucl Med Mol Imaging 2009;36(7):1176-1184

20 Cysique LA, Moffat K, Moore DM, et al. HIV, vascular and aging injuries in the brain of clinically stable HIV-infected adults: a (1)H MRS study. PLoS ONE 2013;8(4):e61738

21 Lentz MR, Kim WK, Kim H, et al. Alterations in brain metabolism during the first year of HIV infection. J Neurovirol 2011;17(3): 220-229

22 Harezlak J, Buchthal S, Taylor M, et al; HIV Neuroimaging Consortium. Persistence of HIV-associated cognitive impairment, inflammation, and neuronal injury in era of highly active antiretroviral treatment. AIDS 2011;25(5):625-633

23 Descamps M, Hyare H, Stebbing J, Winston A. Magnetic resonance imaging and spectroscopy of the brain in HIV disease. J HIV Ther 2008;13(3):55-58

24 Kantarci K. Proton MRS in mild cognitive impairment. J Magn Reson Imaging 2013;37(4):770-777

25 Valcour V, Chalermchai T, Sailasuta N, et al; RV254/SEARCH 010 Study Group. Central nervous system viral invasion and inflammation during acute HIV infection. J Infect Dis 2012;206(2): 275-282

26 Sailasuta N, Ross W, Ananworanich J, et al; RV254/SEARCH 010 protocol teams. Change in brain magnetic resonance spectroscopy after treatment during acute HIV infection. PLoS ONE 2012; 7(11):e49272

27 Iannucci G, Rovaris M, Giacomotti L, Comi G, Filippi M. Correlation of multiple sclerosis measures derived from T2-weighted, T1weighted, magnetization transfer, and diffusion tensor MR imaging. AJNR Am J Neuroradiol 2001;22(8):1462-1467

28 Cardenas VA, Meyerhoff DJ, Studholme C, et al. Evidence for ongoing brain injury in human immunodeficiency virus-positive patients treated with antiretroviral therapy. J Neurovirol 2009; 15(4):324-333

29 Mohamed MA, Barker PB, Skolasky RL, et al. Brain metabolism and cognitive impairment in HIV infection: a 3-T magnetic resonance spectroscopy study. Magn Reson Imaging 2010; 28(9):1251-1257

30 Paul RH, Ernst T, Brickman AM, et al; ACTG 301 team; ACTG 700 team; HIV MRS Consortium. Relative sensitivity of magnetic resonance spectroscopy and quantitative magnetic resonance imaging to cognitive function among nondemented individuals infected with HIV. J Int Neuropsychol Soc 2008;14(5): 725-733

31 Yiannoutsos CT, Nakas CT, Navia BA; proton MRS Consortium. Assessing multiple-group diagnostic problems with multi-dimensional receiver operating characteristic surfaces: application to proton MR Spectroscopy (MRS) in HIV-related neurological injury. Neuroimage 2008;40(1):248-255

32 Ernst T, Jiang CS, Nakama H, Buchthal S, Chang L. Lower brain glutamate is associated with cognitive deficits in HIV patients: a new mechanism for HIV-associated neurocognitive disorder. J Magn Reson Imaging 2010;32(5):1045-1053

33 Chang L, Ernst T, Leonido-Yee M, et al. Highly active antiretroviral therapy reverses brain metabolite abnormalities in mild HIV dementia. Neurology 1999;53(4):782-789

34 Tarasów E, Wiercińska-Drapało A, Jaroszewicz J, et al. Antiretroviral therapy and its influence on the stage of brain damage in patients with HIV - 1H MRS evaluation. Med Sci Monit 2004;10 (Suppl 3):101-106

35 Schifitto G, Yiannoutsos CT, Ernst T, et al; ACTG 5114 Team. Selegiline and oxidative stress in HIV-associated cognitive impairment. Neurology 2009;73(23):1975-1981
36 Robertson KR, Su Z, Margolis DM, et al; A5170 Study Team. Neurocognitive effects of treatment interruption in stable HIVpositive patients in an observational cohort. Neurology 2010; 74(16):1260-1266

37 Schweinsburg BC, Taylor MJ, Alhassoon OM, et al; HNRC Group. Brain mitochondrial injury in human immunodeficiency virusseropositive (HIV+) individuals taking nucleoside reverse transcriptase inhibitors. J Neurovirol 2005;11(4):356-364

38 Klauschen F, Goldman A, Barra V, Meyer-Lindenberg A, Lundervold A. Evaluation of automated brain MR image segmentation and volumetry methods. Hum Brain Mapp 2009;30(4): $1310-1327$

39 Fjell AM, Westlye LT, Amlien I, et al. High consistency of regional cortical thinning in aging across multiple samples. Cereb Cortex 2009;19(9):2001-2012

40 Dal Pan GJ, McArthur JH, Aylward E, et al. Patterns of cerebral atrophy in HIV-1-infected individuals: results of a quantitative MRI analysis. Neurology 1992;42(11):2125-2130

41 Fennema-Notestine C, Ellis RJ, Archibald SL, et al; CHARTER Group. Increases in brain white matter abnormalities and subcortical gray matter are linked to CD4 recovery in HIV infection. J Neurovirol 2013;19(4):393-401

42 Jernigan TL, Archibald SL, Fennema-Notestine C, et al; CHARTER Group. Clinical factors related to brain structure in HIV: the CHARTER study. J Neurovirol 2011;17(3):248-257

43 Dewey J, Hana G, Russell T, et al; HIV Neuroimaging Consortium. Reliability and validity of MRI-based automated volumetry software relative to auto-assisted manual measurement of subcortical structures in HIV-infected patients from a multisite study. Neuroimage 2010;51(4):1334-1344

44 Heindel WC, Jernigan TL, Archibald SL, Achim CL, Masliah E, Wiley CA. The relationship of quantitative brain magnetic resonance imaging measures to neuropathologic indexes of human immunodeficiency virus infection. Arch Neurol 1994;51(11):1129-1135

45 Aylward EH, Henderer JD, McArthur JC, et al. Reduced basal ganglia volume in HIV-1-associated dementia: results from quantitative neuroimaging. Neurology 1993;43(10):2099-2104

46 Aylward EH, Brettschneider PD, McArthur JC, et al. Magnetic resonance imaging measurement of gray matter volume reductions in HIV dementia. Am J Psychiatry 1995;152(7):987-994

47 Stout JC, Ellis RJ, Jernigan TL, et al; HIV Neurobehavioral Research Center Group. Progressive cerebral volume loss in human immunodeficiency virus infection: a longitudinal volumetric magnetic resonance imaging study. Arch Neurol 1998;55(2):161-168

48 Heaps JM, Joska J, Hoare J, et al. Neuroimaging markers of human immunodeficiency virus infection in South Africa. J Neurovirol 2012;18(3):151-156

49 Thompson PM, Dutton RA, Hayashi KM, et al. Thinning of the cerebral cortex visualized in HIV/AIDS reflects CD4+ T lymphocyte decline. Proc Natl Acad Sci U S A 2005;102(43):15647-15652

50 Ances BM, Ortega M, Vaida F, Heaps J, Paul R. Independent effects of HIV, aging, and HAART on brain volumetric measures. J Acquir Immune Defic Syndr 2012;59(5):469-477

51 Ragin AB, Du H, Ochs R, et al. Structural brain alterations can be detected early in HIV infection. Neurology 2012;79(24): 2328-2334

52 Cohen RA, Harezlak J, Schifitto G, et al. Effects of nadir CD4 count and duration of human immunodeficiency virus infection on brain volumes in the highly active antiretroviral therapy era. J Neurovirol 2010;16(1):25-32

53 Patel SH, Kolson DL, Glosser G, et al. Correlation between percentage of brain parenchymal volume and neurocognitive performance in HIV-infected patients. AJNR Am J Neuroradiol 2002; 23(4):543-549

54 Cohen RA, Harezlak J, Gongvatana A, et al; HIV Neuroimaging Consortium. Cerebral metabolite abnormalities in human immunodeficiency virus are associated with cortical and subcortical volumes. J Neurovirol 2010;16(6):435-444 
55 Pfefferbaum A, Rosenbloom MJ, Sassoon SA, et al. Regional brain structural dysmorphology in human immunodeficiency virus infection: effects of acquired immune deficiency syndrome, alcoholism, and age. Biol Psychiatry 2012;72(5):361-370

56 Castelo JM, Courtney MG, Melrose RJ, Stern CE. Putamen hypertrophy in nondemented patients with human immunodeficiency virus infection and cognitive compromise. Arch Neurol 2007; 64(9):1275-1280

57 Thames AD, Foley JM, Wright MJ, et al. Basal ganglia structures differentially contribute to verbal fluency: evidence from Human Immunodeficiency Virus (HIV)-infected adults. Neuropsychologia 2012;50(3):390-395

58 Becker JT, Sanders J, Madsen SK, et al; Multicenter AIDS Cohort Study. Subcortical brain atrophy persists even in HAART-regulated HIV disease. Brain Imaging Behav 2011;5(2):77-85

59 Sullivan EV, Rosenbloom MJ, Rohlfing T, Kemper CA, Deresinski S, Pfefferbaum A. Pontocerebellar contribution to postural instability and psychomotor slowing in HIV infection without dementia. Brain Imaging Behav 2011;5(1):12-24

60 Li C, Zhang X, Komery A, Li Y, Novembre FJ, Herndon JG. Longitudinal diffusion tensor imaging and perfusion MRI investigation in a macaque model of neuro-AIDS: a preliminary study. Neuroimage 2011;58(1):286-292

61 Kallianpur KJ, Shikuma C, Kirk GR, et al. Peripheral blood HIV DNA is associated with atrophy of cerebellar and subcortical gray matter. Neurology 2013;80(19):1792-1799

62 Ragin AB, D'Souza G, Reynolds S, et al. Platelet decline as a predictor of brain injury in HIV infection. J Neurovirol 2011; 17(5):487-495

63 Durazzo TC, Rothlind JC, Cardenas VA, Studholme C, Weiner MW, Meyerhoff DJ. Chronic cigarette smoking and heavy drinking in human immunodeficiency virus: consequences for neurocognition and brain morphology. Alcohol 2007;41(7):489-501

64 McMurtray A, Nakamoto B, Shikuma C, Valcour V. Small-vessel vascular disease in human immunodeficiency virus infection: the Hawaii aging with HIV cohort study. Cerebrovasc Dis 2007;24(23):236-241

65 Becker JT, Maruca V, Kingsley LA, et al; Multicenter AIDS Cohort Study. Factors affecting brain structure in men with HIV disease in the post-HAART era. Neuroradiology 2012;54(2):113-121

66 Towgood KJ, Pitkanen M, Kulasegaram R, et al. Mapping the brain in younger and older asymptomatic HIV-1 men: frontal volume changes in the absence of other cortical or diffusion tensor abnormalities. Cortex 2012;48(2):230-241

67 Valcour VG. HIV, aging, and cognition: emerging issues. Top Antivir Med 2013;21(3):119-123

68 Tate DF, Sampat M, Harezlak J, et al; HIV Neuroimaging Consortium. Regional areas and widths of the midsagittal corpus callosum among HIV-infected patients on stable antiretroviral therapies. J Neurovirol 2011;17(4):368-379

69 Christensen A, Russ S, Rambaran N, Wright SW. Patient perspectives on opt-out HIV screening in a Guyanese emergency department. In Health 2012;4(3):185-191

70 Turner MR, Modo M. Advances in the application of MRI to amyotrophic lateral sclerosis. Expert Opin Med Diagn 2010; 4(6):483-496

71 Chanraud S, Zahr N, Sullivan EV, Pfefferbaum A. MR diffusion tensor imaging: a window into white matter integrity of the working brain. Neuropsychol Rev 2010;20(2):209-225

72 Wycoco V, Shroff M, Sudhakar S, Lee W. White matter anatomy: what the radiologist needs to know. Neuroimaging Clin N Am 2013;23(2):197-216

73 Gongvatana A, Cohen RA, Correia S, et al. Clinical contributors to cerebral white matter integrity in HIV-infected individuals. J Neurovirol 2011;17(5):477-486

74 Wu Y, Storey P, Cohen BA, Epstein LG, Edelman RR, Ragin AB. Diffusion alterations in corpus callosum of patients with HIV. AJNR Am J Neuroradiol 2006;27(3):656-660
75 Thurnher MM, Castillo M, Stadler A, Rieger A, Schmid B, Sundgren PC. Diffusion-tensor MR imaging of the brain in human immunodeficiency virus-positive patients. AJNR Am J Neuroradiol 2005;26(9):2275-2281

76 Pomara N, Crandall DT, Choi SJ, Johnson G, Lim KO. White matter abnormalities in HIV-1 infection: a diffusion tensor imaging study. Psychiatry Res 2001;106(1):15-24

77 Müller-Oehring EM, Schulte T, Rosenbloom MJ, Pfefferbaum A, Sullivan EV. Callosal degradation in HIV-1 infection predicts hierarchical perception: a DTI study. Neuropsychologia 2010; 48(4):1133-1143

78 Stebbins GT, Smith CA, Bartt RE, et al. HIV-associated alterations in normal-appearing white matter: a voxel-wise diffusion tensor imaging study. J Acquir Immune Defic Syndr 2007;46(5):564-573

79 Ragin AB, Wu Y, Storey P, Cohen BA, Edelman RR, Epstein LG. Diffusion tensor imaging of subcortical brain injury in patients infected with human immunodeficiency virus. J Neurovirol 2005; 11(3):292-298

80 Filippi CG, Ulug AM, Ryan E, Ferrando SJ, van Gorp W. Diffusion tensor imaging of patients with HIV and normal-appearing white matter on MR images of the brain. AJNR Am J Neuroradiol 2001; 22(2):277-283

81 Ragin AB, Storey P, Cohen BA, Edelman RR, Epstein LG. Disease burden in HIV-associated cognitive impairment: a study of whole-brain imaging measures. Neurology 2004;63(12): 2293-2297

82 Ragin AB, Storey P, Cohen BA, Epstein LG, Edelman RR. Whole brain diffusion tensor imaging in HIV-associated cognitive impairment. AJNR Am J Neuroradiol 2004;25(2):195-200

83 Pfefferbaum A, Rosenbloom MJ, Rohlfing T, Kemper CA, Deresinski S, Sullivan EV. Frontostriatal fiber bundle compromise in HIV infection without dementia. AIDS 2009;23(15):1977-1985

84 Hoare J, Westgarth-Taylor J, Fouche JP, et al. A diffusion tensor imaging and neuropsychological study of prospective memory impairment in South African HIV positive individuals. Metab Brain Dis 2012;27(3):289-297

85 Stubbe-Drger B, Deppe M, Mohammadi S, et al; German Competence Network HIV/AIDS. Early microstructural white matter changes in patients with HIV: a diffusion tensor imaging study. BMC Neurol 2012;12:23

$86 \mathrm{Du} \mathrm{H}, \mathrm{Wu} \mathrm{Y}$, Ochs R, et al. A comparative evaluation of quantitative neuroimaging measurements of brain status in HIV infection. Psychiatry Res 2012;203(1):95-99

87 Zhu T, Zhong J, Hu R, et al. Patterns of white matter injury in HIV infection after partial immune reconstitution: a DTI tract-based spatial statistics study. J Neurovirol 2013;19(1):10-23

88 Wright PW, Heaps JM, Shimony JS, Thomas JB, Ances BM. The effects of HIV and combination antiretroviral therapy on white matter integrity. AIDS 2012;26(12):1501-1508

89 Chen Y, An H, Zhu H, et al. White matter abnormalities revealed by diffusion tensor imaging in non-demented and demented HIV+ patients. Neuroimage 2009;47(4):1154-1162

90 Rauch A, Rainer G, Logothetis NK. The effect of a serotonininduced dissociation between spiking and perisynaptic activity on BOLD functional MRI. Proc Natl Acad Sci U S A 2008;105(18): 6759-6764

91 Zhang D, Raichle ME. Disease and the brain's dark energy. Nat Rev Neurol 2010;6(1):15-28

92 Ogawa S. Finding the BOLD effect in brain images. Neuroimage 2012;62(2):608-609

93 Chang L, Speck O, Miller EN, et al. Neural correlates of attention and working memory deficits in HIV patients. Neurology 2001; 57(6):1001-1007

94 Ances B, Vaida F, Ellis R, Buxton R. Test-retest stability of calibrated BOLD-fMRI in HIV- and HIV+ subjects. Neuroimage 2011; 54(3):2156-2162

95 Ances BM, Roc AC, Korczykowski M, Wolf RL, Kolson DL. Combination antiretroviral therapy modulates the blood oxygen level- 
dependent amplitude in human immunodeficiency virus-seropositive patients. J Neurovirol 2008;14(5):418-424

96 Chang L, Tomasi D, Yakupov R, et al. Adaptation of the attention network in human immunodeficiency virus brain injury. Ann Neurol 2004;56(2):259-272

97 Ernst T, Chang L, Jovicich J, Ames N, Arnold S. Abnormal brain activation on functional MRI in cognitively asymptomatic HIV patients. Neurology 2002;59(9):1343-1349

98 Ernst T, Yakupov R, Nakama H, et al. Declined neural efficiency in cognitively stable human immunodeficiency virus patients. Ann Neurol 2009;65(3):316-325

99 Juengst SB, Aizenstein HJ, Figurski J, Lopez OL, Becker JT. Alterations in the hemodynamic response function in cognitively impaired HIV/ AIDS subjects. J Neurosci Methods 2007;163(2):208-212

100 Maki PM, Cohen MH, Weber K, et al. Impairments in memory and hippocampal function in HIV-positive vs HIV-negative women: a preliminary study. Neurology 2009;72(19):1661-1668

101 Tracey I, Hamberg LM, Guimaraes AR, et al. Increased cerebral blood volume in HIV-positive patients detected by functional MRI. Neurology 1998;50(6):1821-1826
102 Du Plessis S, Vink M, Joska J, Koutsilieri E, Stein DJ, Emsley R. HIV infection and the fronto-striatal system: a systematic review and meta-analysis of fMRI studies. AIDS 2014; In press

103 Thomas JB, Brier MR, Snyder AZ, Vaida FF, Ances BM. Pathways to neurodegeneration: effects of HIV and aging on resting-state functional connectivity. Neurology 2013;80(13):1186-1193

104 Bonnet F, Amieva H, Marquant F, et al; S CO3 Aquitaine Cohort. Cognitive disorders in HIV-infected patients: are they HIV-related? AIDS 2013;27(3):391-400

105 Fennema-Notestine C, Ellis RJ, Archibald SL, et al; CHARTER Group.Increases in brain white matter abnormalities and subcortical gray matter are linked to CD4 recovery in HIV infection. J Neurovirol 2013;19(4):393-401

106 Müller-Oehring EM, Schulte T, Rosenbloom MJ, Pfefferbaum A, Sullivan EV. Callosal degradation in HIV-1 infection predicts hierarchical perception: a DTI study. Neuropsychologia 2010; 48(4):1133-1143

107 Pfefferbaum A, Rosenbloom MJ, Rohlfing T, Kemper CA, Deresinski S, Sullivan EV. Frontostriatal fiber bundle compromise in HIV infection without dementia. AIDS 2009;23(15):1977-1985 